\title{
Radial shortening for the treatment of Kienböck's disease
}

\author{
S. Amillo, R. Martinez-Peric, and R. H. Barrios
}

Department of Orthopaedic Surgery and Traumatology, University Clinic, School of Medicine, University of Navarra, Pamplona, Spain

\author{
Reprint requests to: S. Amillo \\ Clínica Universitaria de Navarra \\ Apartado 193, E-31080 Pamplona, Spain
}

\section{SUMMARY}

Twelve patients with Kienböck's disease were treated by radial shortening. Eight patients were in stage II and four in stage III. After an average of 5 years, relief of pain was satisfactory in 10 patients; 8 were in stage II before operation and 2 in Stage III. Two patients were dissatisfied because they had persistent pain; both were in Stage III before surgery. The range of motion improved moderately. Nonunion at the site of radial osteotomy did not occur. Radiographs at follow up showed consolidation and healing of the lunate in 2 patients, nonprogression of the disease in 9 and increase of the carpal collapse in 1 . The procedure helps to prevent further collapse of the lunate especially in stage II and in some patients in stage III.

\section{RÉSUMÉ}

Douze patients atteints de maladie de Kienböck ont été traités par ostéotornie radiale de raccourcissernent. Huit d'entre eux étaient au stade II et quatre au stade III. Avec un recul de 5 ans, les douleurs étaient soulagées de façon satisfaisante dans 10 cas, 8 de stade II et 2 de stade III. Deux malades présentaient des douleurs persistantes (tous deux au stade III avant l'opératition). La mobilité du poignet était habituellement légérement améliorée. Il n'y a pas eu de pseudarthrose de l'ostéotomie radiale. Les radiographies ont montré une consolidation et une récupération de la trophicité du semi-lunaire dans 2 cas, un arrêt de la progression de la maladie chez 9 autres et une augmentation du pincement carpien dans un cas. En conclusion, cette opération permet de prévenir l'écrasement du semi-lunaire, notamment au stade II et chez quelques malades du stade III. 


\section{INTRODUCTION}

Since 1910, when Kienböck described avascular necrosis with collapse of the lunate [13], no definitive treatment for this condition has been established. In 1928 Hulten [2] found abnormal anatomical relations between the radius and the proximal carpal row. In $78 \%$ of his patients with Kienböck's disease there was an ulnar minus variance of $23 \%$. Antuña Zapico [3] described a relationship between the shape of the lunate and the length of the ulna. He found that the lunate Typo 1 (presenting a proximal apex) had a weaker trabecular pattern when related to ulnar minus variance. It is universally accepted that ulnar minus variance is a contributing factor in the genesis of Kienböck's disease $[2,3,4,5,8,9,11$, $12,15]$.

Joint-levelling operations with ulnar lengthening or radial shortening have produced excellent late results which have been attributed to the postoperative changes in the radiolunate relationship $[2,4,9,15]$.

\section{MATERIAL AND METHODS}

We reviewed 12 patients treated by radial shortening between 1980 and 1989 . There were 11 males and 1 female. The average age was 25 years, range 18-57, and the average follow up was 5 years, range 3-9. Eleven patients had unilateral involvement with 9 in the right hand and 2 in the left; one had both lunate bones involved. All the patients were right handed, and 7 had occupations requiring heavy labour. Six described a hyperextension injury of the involved wrist.

All the patients complained of wrist pain and 4 were unable to perform their work. The duration of symptoms before operation averaged 1 year. Wrist motion, on average, was reduced when compared with the contralateral, uninvolved wrist with volar flexion of $70 \%$, dorsiflexion $85 \%$, radial deviation $60 \%$ and ulnar deviation $60 \%$. Prono-supination was full. Grip strength was decreased in all the patients compared with the opposite side.

Standard radiographs were made in all patients, and a dynamic examination was carried out in those with a high degree of carpal collapse in whom carpal instability was suspected. The ulnar variance average was $-4.5 \mathrm{~mm}$ (range 0 to $-8.5 \mathrm{~mm}$ ). The ulna plus condition was not present in any patient. The degree of carpal collapse was measured by the method proposed by Youm et al. [17]. This uses the ratio of carpal height to the length of the third metacarpal. This ratio in the normal population is $0.54 \pm 0.03$. The average carpal height was 0.5 (range $0.44-0.56$ ). No patient had carpal instability. Using the method for staging described by Lichtmann, Mack, MacDonald, Gunther and Wilson [14] 8 patients were in stage II and 4 in stage III. We did not use joint-levelling operations in patients with stage IV disease.

\section{SURGICAL PROCEDURE}

A transverse osteotomy was performed at the lower end of the radius removing a segment of variable length depending on the ulnar variance calculated before operation. A dynamic compression plate with 4, 5 or 6 holes was used and was loosely fixed at one side of the osteotomy site before removal of the bone segment (Fig. 1). The dynamic compression 
plate produces rigid fixation. We did not use cast immobilization after the operation in order to permit early motion of the wrist and digits.

\section{RESULTS}

All 12 patients were available for examination at follow up. The average consolidation time was 3 months and there was no malunion, nonunion or infection. After operation the ulnar variance was virtually normal. Six patients obtained complete pain relief and returned to their original occupations.

Their clinical grades before surgery were 5 in stage II and 1 in stage III. Four patients had mild pain on repetitive wrist motion, 3 in stage II and 1 in stage III; 2 remained unchanged, both in stage III. Wrist motion improved slightly to volar flexion of $80 \%$, dorsiflexion $85 \%$, radial deviation $60 \%$ and ulnar deviation $60 \%$ compared with the other side. Grip strength improved in 10 patients and did not change in 2.

We observed improvement of the carpal height in 2 patients, with evidence of consolidation and healing of the lunate (Figs. 2-5). The radiographic density of the lunate changed in 4 patients with an apparent decrease in sclerosis; 5 showed no change, and 1 had increased sclerosis with collapse of the carpus. We did not observe subluxation at the distal radioulnar joint.

\section{DISCUSSION}

A review of the literature shows a large number of different surgical procedures either for the correction of the multiple factors leading to lunate collapse or for the treatment of the collapse itself. These range from simple immobilization to wrist arthrodesis $[1,6,7,8,10$, 14, 16]. Silastic implants have been used extensively $[1,10,14,16]$ but problems have been reported during insertion. Subluxation of the implant with possible associated neurological damage has also occurred. This may be partially solved by a careful reconstruction of the volar capsule, by preservation of the volar cortex of the lunate and by simultaneous intercarpal arthrodesis when carpal instability is present. Joint levelling procedures have the advantage of avoiding arthrotomy of the wrist and also treat ulna minus variance, one of the principal predisposing factors in this condition. The option to perform prosthetic replacement still remains. Presumably the reduction of forces concentrated at this joint surface facilitates the healing and revascularization of the lunate. We believe that the presence of osteoarthritis is a contraindication for the operation.

In our experience, radial shortening is technically easier than ulnar lengthening and does not require bone grafting. Our clinical results are comparable to those obtained by Armistead, Linscheid, Dobyns and Beckenbaugh [4] with the ulnar lengthening procedure, with the exception of the rate of nonunion. They reported an incidence of $15 \%$ nonunion with satisfactory results after replating and bone grafting. Ulnar lengthening produced a $10 \%$ decrease in ulnar deviation, possibly related to the ulnar plus variance obtained after surgery. In our series we observed limitation in ulnar deviation in 3 patients with a postoperative ulnar plus position. There is less chance of postoperative overcorrection with the radial shortening procedure. 
Ten of our 12 patients had a good result. Eight were in stage II and 2 in stage III before operation. They had a slight improvement in wrist movement and an increase in grip strength. Two patients had a poor result, with severe pain and decreased wrist motion. Both were in stage III prior to surgery. We believe that radial shortening has a better result in stage II preventing further collapse of the lunate.

\section{REFERENCES}

1. Agerholm JC, Goodfellow JW (1963) A vascular necrosis of the lunate bone treated by excision and prosthetic replacement. J Bone Joint Surg [Br] 45: 10-116

2. Almquist EE, Burns JF (1982) Radial shortening for the treatment of Kienböck disease. A 5 to 10 year follow up. J Hand Surg 7: 348-352

3. Antuña Zapico JM (1966) Malacia del semilunar. Tesis doctoral, Universidad de Valladolid, Industrias y editorial Sever Cuesta, Valladolid, España

4. Armistead RD, Linscheid RL, Dobyns JH, Beckenbaugh RD (1982) Ulnar lengthening in the treatment of Kienböck' s disease. J Bone Joint Surg [Am] 64: 170-178

5. Beckenbaugh RD, Shives TC, Dobyns JH, Linscheid RL (1980) Kienböck's disease: The natural history of Kienböck disease and considerations of lunate fractures. Clin Orthop 149: 98-106

6. Blanco RH (1985) Excision of the lunate in Kienböck's disease: long term results. J Hand Surg 10A: 1008-1013

7. Carroll RE (1985) Discussion of carpal collapse deformity after lunate resection for Kienböck's disease. J Hand Surg 8: 612

8. Chuinard RG, Zeman SC (1980) Kienböck's disease: an analysis and rationale for treatment by capitate-hamate fusion. Orthop Trans 4: 18

9. Eiken O, Niechajev I (1980) Radius shortening in malacia of the lunate. Scand J Plast Reconstr Surg 14: 191-196

10. Evans G, Burke FD, Barton JN (1986) A comparison of conservative treatment and silicone replacement arthroplasty in Kienböck disease. J Hand Surg 11B: 98-102

11. Gelberman RH, Salomon PB, Jurist JM, Posch JL (1975) Ulnar variance in Kienböck's disease. J Bone Joint Surg [Am] 57: 674-676

12. Hulten O (1928) Über Anatomische Variationen der Handgelenkknochen. Acta Radiol Scand 9: 155-168

13. Kienböck R (1910) Über traumatische Malazie des Mondbeins und Kompression Fracturen. Fortschr Roentgenstrahlen 16: 77-103

14. Lichtman DM, Mack GR, MacDonald RI, Gunther SF, Wilson JN (1977) Kienböck's disease: the role of silicone replacement arthroplasty. J Bone Joint Surg [Am] 59: 899-908

15. Rock MG, Roth JH, Martin L (1991) Radial shortening osteotomy for treatment of Kienböck's disease. J Hand Surg 16A: 454 -460

16. Swanson AB, Maupin BK, Swanson G de Groot, Ganzhorn RW, Moss SH (1985) Lunate implant resection arthroplasty: long term results. J Hand Surg 10A: 1013-1024

17. Youm Y, Mac Murty RY, Flatt AE, Gillespie TE (1978) Kinemetics of the wrist. An experimental study radial-ulnar deviation and flexion extension. J Bone Joint Surg [Am] 60A: 423 


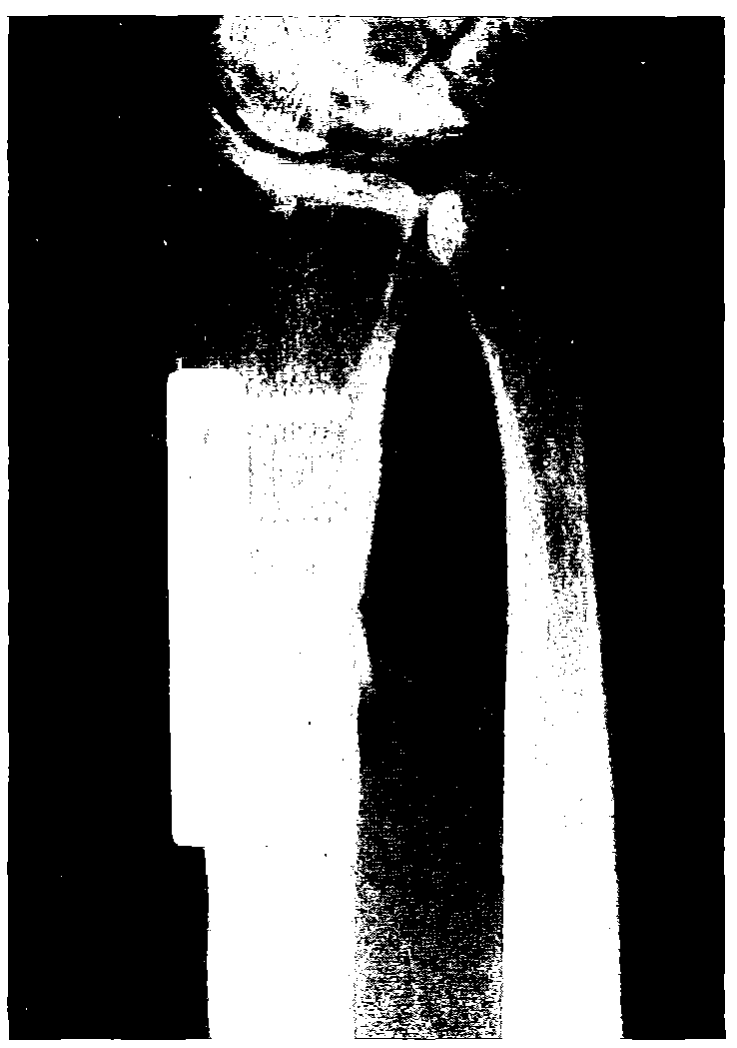

Figure 1. AP radiograph of the osteotomy of the radius
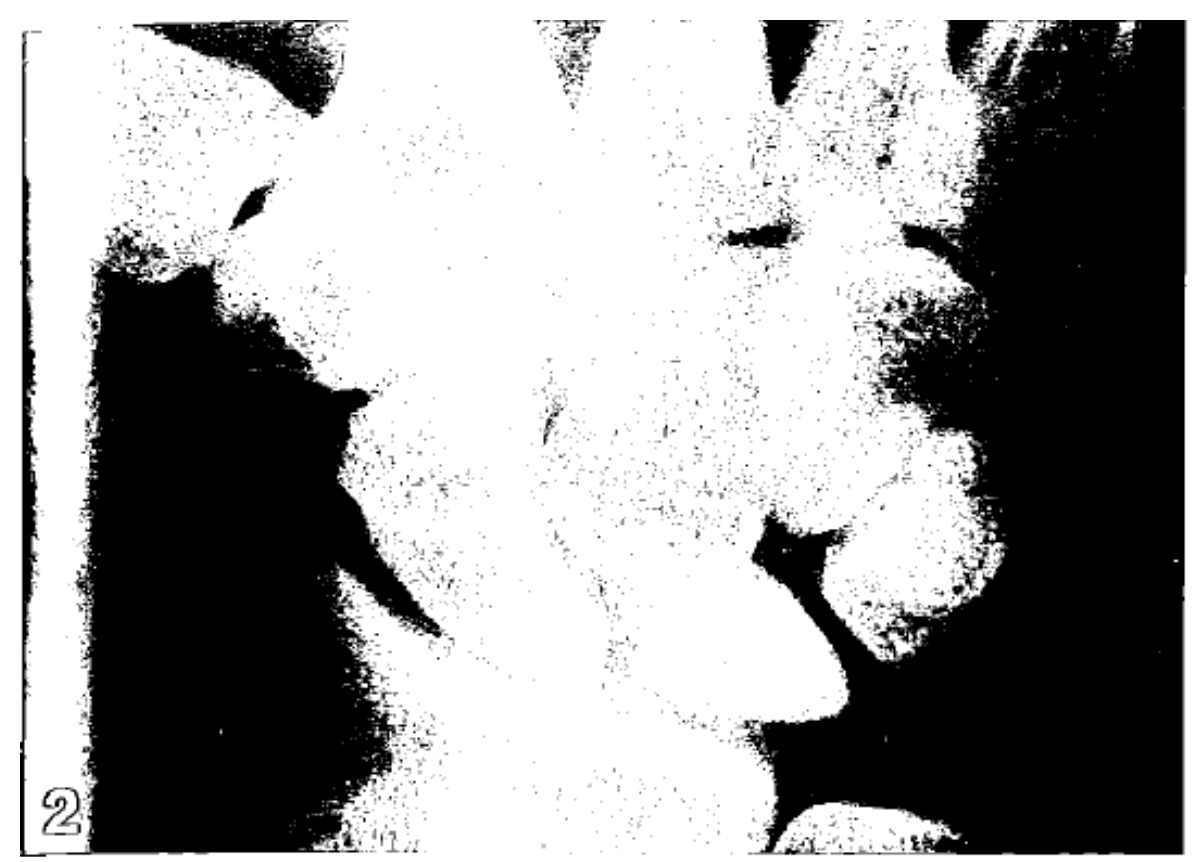

Figure 2. Early stage III Kienböck's disease in a 24 year old man 


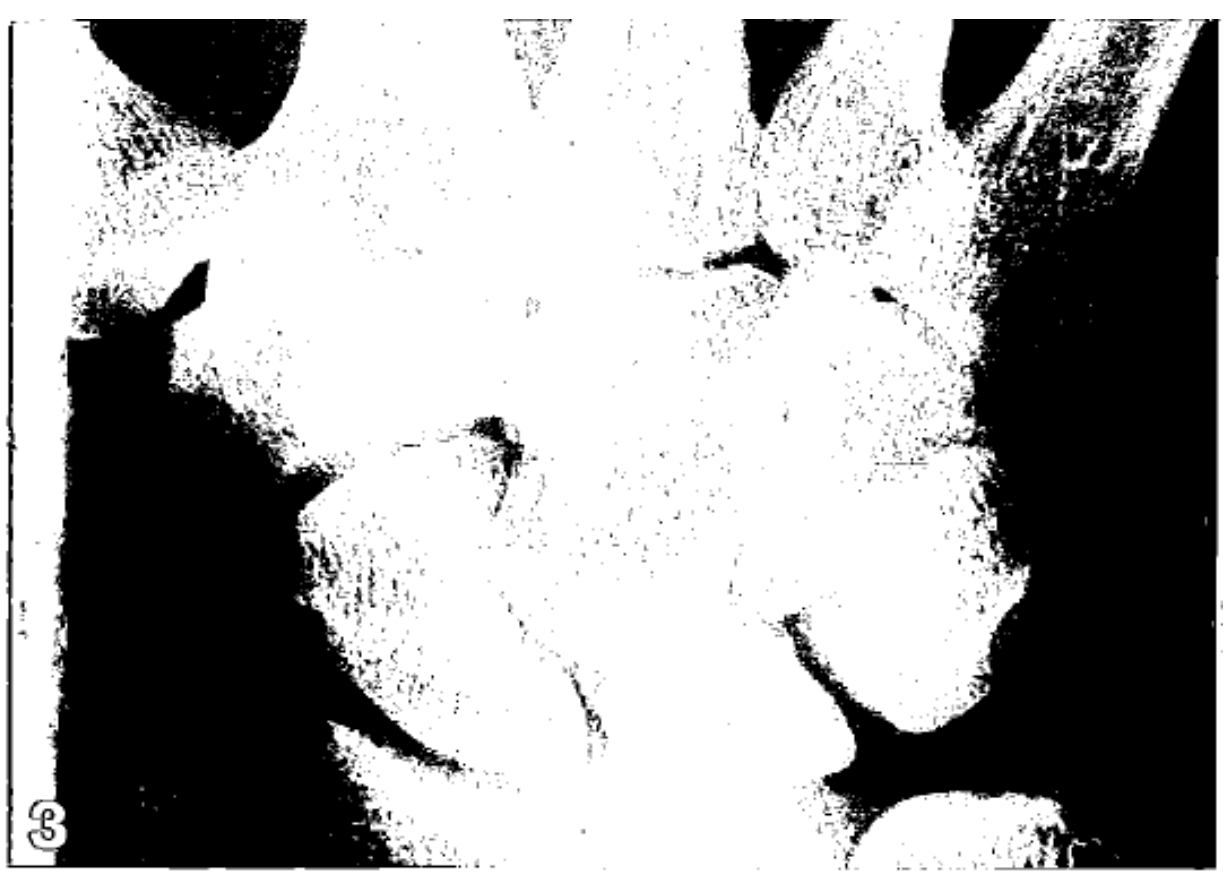

Figure 3. The same patient as in Fig. 2 showing a complete healing of the lunate five years after operation

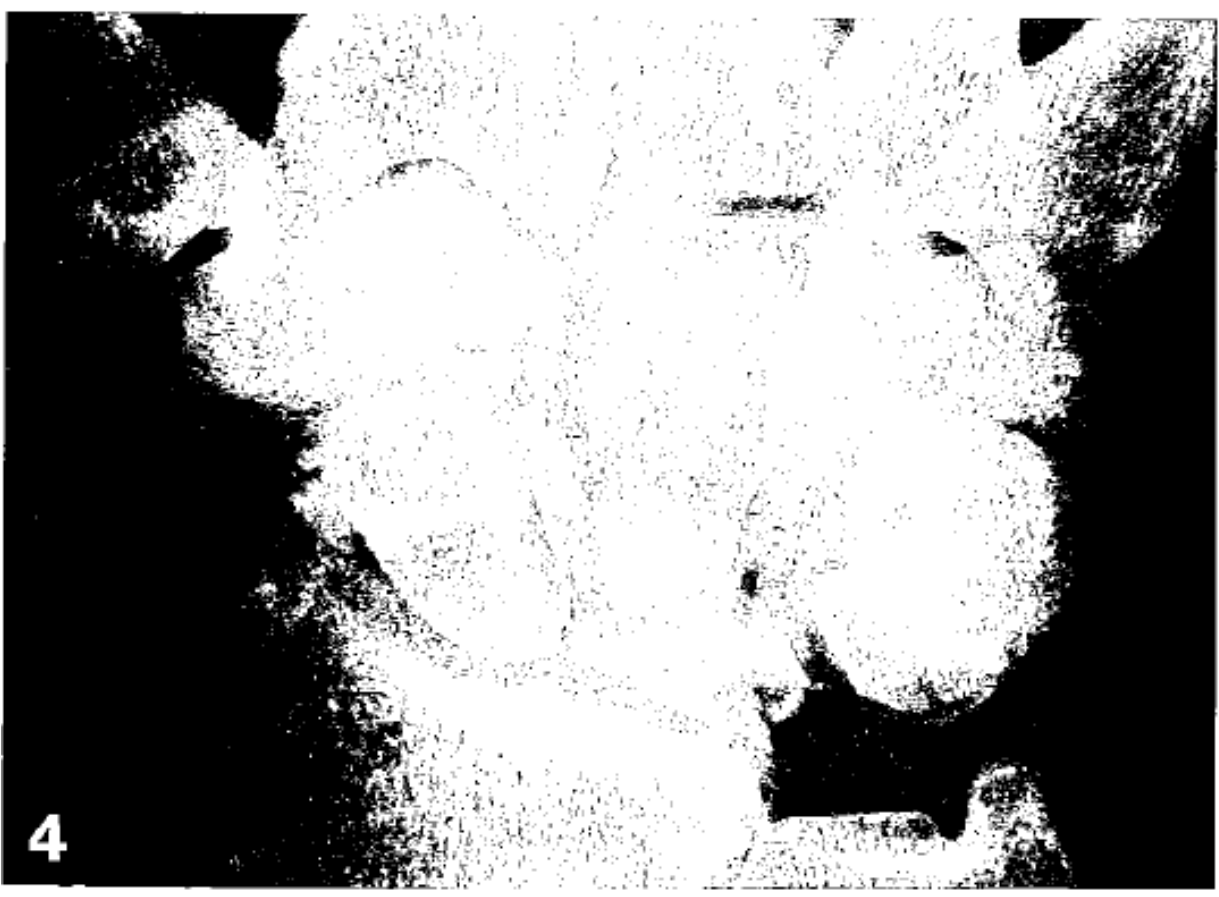

Figure 4. Late stage III of lunatomalacia in a 30 year old man with complete collapse of the lunate and incipient osteoarthritic changes 


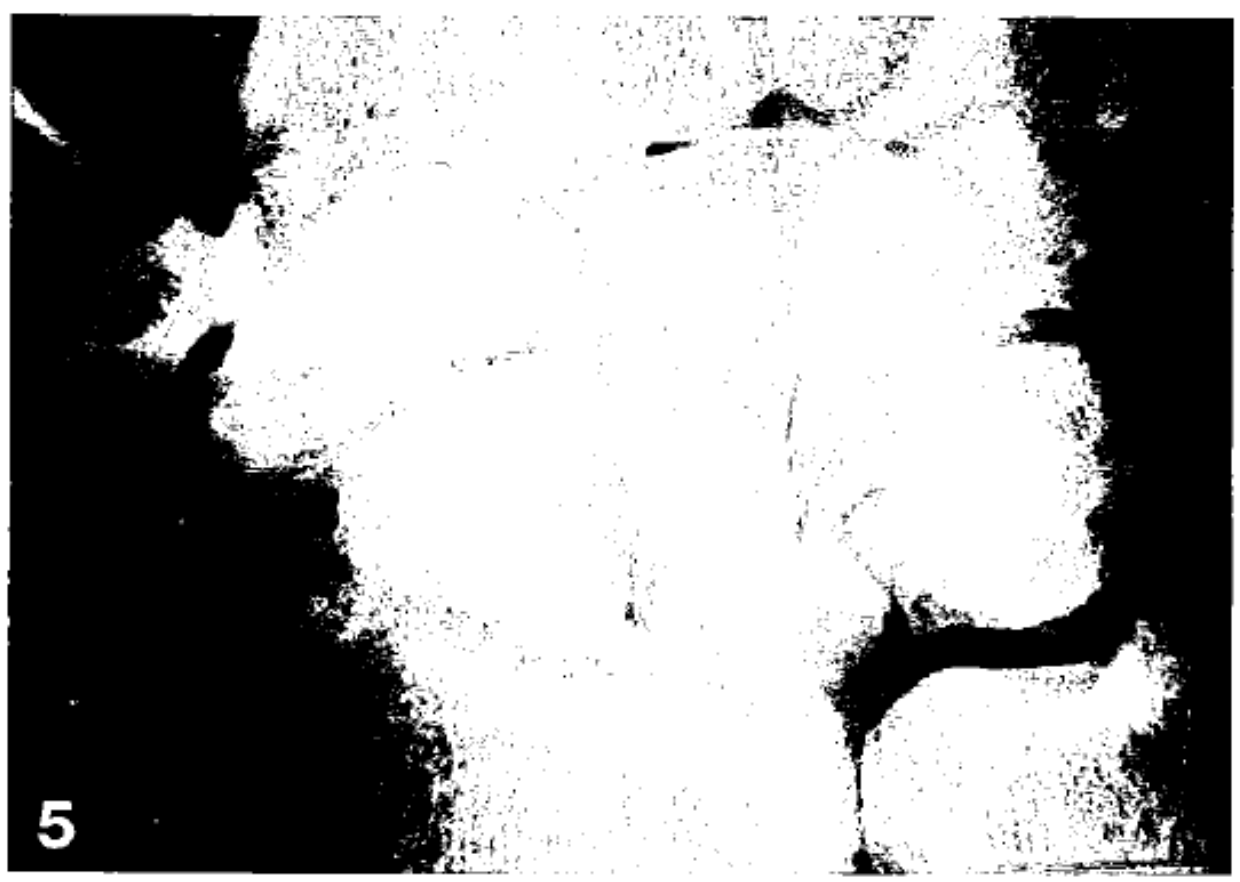

Figure 5. The same patient as in Fig. 4, 9 years after surgery, showing an increase in carpal height and partial healing of the lunate 